\title{
Tuning as Instrument of Systematic Higher Education Reform and Quality Enhancement: The African Experience ${ }^{1}$
}

\author{
Karola Hahn and Damtew Teferra
}

\begin{abstract}
This article explores the state of higher education in Africa as it relates to the experience and lessons learned in the Tuning African higher education project. It analyses the specific African dimension of the methodology, its contribution to the reform efforts in teaching and learning, and the critical issues vital for quality enhancement and harmonization of higher education in Africa.
\end{abstract}

Keywords: Tuning; harmonization; curriculum development; reform; quality; higher education; Africa; regional integration.

\section{Introduction}

African higher education is undergoing major transformation driven by the "massification" of the system. As the system has shown phenomenal growth, in the face of increasing global competitiveness in production of knowledge-now undoubtedly identified as "key driver for socio-economic development"2 and its importance unparalleled "in history" 3 - the imperative of quality enhancement has become paramount. Higher education in Africa has (re)gained a prominent place in major regional policies and strategies after decades of negligence. At the continental level, the African Union Commission has declared the revitalisation of higher education and its quality enhancement as one of its priority areas for the future development and the regional integration of Africa. The outcome of these new policies have been instrumental in spawning numerous sub-regional, regional and international higher education initiatives, including the harmonization and tuning of higher education in Africa.

Harmonization - a multidimensional and multi-actor process taking place at different system levels that promotes the integration of the Higher

${ }^{1}$ Opinions expressed in this article do not necessarily reflect the views of the Steering Committee of Tuning, the UKZN or GIZ/AUC or others mentioned here.

${ }^{2}$ World Bank (WB), Constructing Knowledge Societies: New Challenges for Tertiary Education, Washington, D.C.: The World Bank Group, 2002.

${ }^{3}$ United Nations Organization for Education, Science and Culture (UNESCO), "2009 World Conference on Higher Education," UNESCO, 2009, http://www.unesco.org/en/wche2009/. 
Education Space in the region-is intended to be achieved by collaborating across borders, sub-regionally and regionally, in curriculum development, educational standards and quality assurance, joint structural convergence, consistency of systems as well as compatibility, recognition and transferability of degrees to facilitate mobility. ${ }^{4}$ One of the broadly tested sets of instruments to effectively implement harmonization in an academically driven approach is the Tuning Methodology.

The Tuning Methodology was developed in Europe to implement the decisions of the Bologna Declaration (Bologna Process) in developing curricula, reforming existing curricula, improving the teaching, learning and assessment, facilitating mobility and contributing to the structural compatibility of studies as well as the recognition of degrees. So far more than 2000 universities have employed the Tuning methodology to reform their curriculum, teaching, learning and assessment. Not only universities (and their leaders, managers, academic staff, students and graduates) but also ministries, agencies, employer and professional associations as well as students have been involved in the project. So far, tuning projects have been completed in more than 60 countries around the world including Europe, Latin America, Russia and the United States. Projects have recently started in Australia, India and China. ${ }^{5}$

The Tuning approach has also been introduced to Africa. In this article we document and analyse the African experience with Tuning Africa which has gone through a Feasibility Study (2010) and a Pilot Project from 20112013 involving 57 African universities and various stakeholders from the higher education sector in Africa.

\section{Tuning: An international higher education reform tool}

Tuning higher education is a systematic and consultative process that collaboratively engages a host of internal and external stakeholders led by academics to identify, define and develop curricula and programs in view of their effective implementation, assessment outcomes and competences. ${ }^{6}$ The

${ }^{4}$ Karola Hahn and Damtew Teferra, "Harmonization and Tuning: Integrating the Space of African Higher Education," Center for International Higher Education (CIHE), Boston College, 2012, https://htmldbprod.bc.edu/prd/f?p=2290:4:0::NO:RP,4:P0_CONTENT_ ID:116932. January 30, 2012.

5 Tuning Educational Structures in Europe (Tuning Europe), http://www.unideusto.org/ tuningeu/.

${ }^{6}$ Damtew Teferra, "Harmonization and Tuning: The African Experience," a paper presented at the Africa-EU Joint Policy Workshop 'On Linking Institutional Evaluation 
Tuning methodology provides a unique opportunity for academics to engage in an in-depth dialogue with their colleagues in similar (and related) disciplines or thematic areas across borders. While the primary focus of Tuning is regional, it can also be used in a country where common mechanisms, understanding and standards across subject areas or thematic programs are uncommon or unavailable.

A Tuning Project generally starts with a stocktaking of the structural elements of programs of a subject area or a thematic area of a program such as water, energy, sustainable development, or gender. The stocktaking considers the length of the program, the structure of the academic calendar (a year, a semester, a trimester or other structure e.g. presence and e-learning phases), and the program's content structure such as core topics addressed, and specializations. It also takes into consideration mandatory and elective modules, forms and sequences of assessment, degrees awarded, the underlying credit system and its principles (as in contact hour based or workload based), and the professional or academic entitlements of the degree.

In a second step, a stakeholder landscape is laid out. This stakeholder landscape comprises all organized actors that are relevant to the (reform of) respective programs under consideration. It comprises "primary" ministries such as education, higher education, science and technology, and also other ministries depending on the subject area or theme of the program. The stakeholder landscape also includes other regulatory bodies on both public and private spheres such as accreditation agencies, quality assurance agencies, professional associations, other universities offering the same or similar programs, major public and private employers and their associations or lobby groups, unions, student associations, and other intermediary bodies (e.g. national or regional university associations) and networks (universities, thematic networks, alumni). The stakeholder landscape may vary substantially between the countries and also within a country depending on the subject areas and themes.

In a third step the program-related generic competences and subjectspecific competences are discussed and mandatory competences, that a graduate of a program is supposed to acquire, are outlined. Ideally, the intended achievements of these competences are laid down thoroughly according to each study year or tier of the study program. The identification of indicators and their assessment remains a challenging process. This step generally requires an extensive reflection and discussion and joint consultation in the Tuning group.

Practices. Quality Rating Mechanisms and Reinforcing Quality Assurance at Continental Level', Accra (Ghana), 18-19 December 2012. 
In a next step, a survey questionnaire (online- and paper-based) and interviews are conducted with stakeholder groups that include students, alumni, academic staff and employers. The questionnaires and interviews focus on program- related generic competences and subject-specific competences that a graduate should have and rated according to their importance and achievement in a given program. The responses of the four stakeholder groups on the three variables, i.e. importance, achievement and ranking are then analyzed and compared. These data provide the ground for profound discussions on the reform needs of a program.

In a fifth step, the so-called meta-profile of the programs is abstracted and an ideal meta-profile of a reformed "African" program is developed jointly. The meta-profile is developed on the basis of the results of discussions in step four, and a correlation between the general African generic competences as well as the generic competences and subject-specific competences of the program compiled in different clusters. These clustered meta-profiles of programs can then serve as a frame of reference of those institutions that strive to reform their curricula and enhance the quality of teaching, learning and assessment. Existing programs could be compared with this referential "ideal" rendering. The outcome of the comparative analysis indicates the potential reform needs of a program and may serve as an orientation for the revision and further development of curricula.

The entire "toolkit" of the Tuning methodology includes developing appropriate methods of teaching, learning and assessment (TLA) as well as quality enhancement (QE). Due to time constraints, these core issues could not yet be addressed in depth in the "African Higher Education Harmonization and Tuning" pilot project. It is planned to address these issues in the future project phases.

\section{Regional Cooperation Scenes}

As noted above, a few years ago a paradigm shift on the role of higher education for continental development has started, identifying higher education as a key driver for development. ${ }^{7}$ This shift has been instrumental in revitalization and broad reform efforts in the continent driven by national, regional and international imperatives. Harmonization and Tuning of Higher Education in Africa is one such core project in the implementation of the continent-wide and regional initiatives, to help harmonise, reform and

7 World Bank (WB), Accelerating Catch-Up. Tertiary Education for Growth in SubSaharan Africa. Washington, D.C.: The World Bank Group, 2009. 
enhance quality in higher education as well as promote the responses of higher education to the continent's development needs and objectives by improving the relevance of higher education and the employability of graduates.

The policy of Harmonization of the African Higher Education Systems was launched by African Union Commission as part of its strategic objectives to bring closer member states and integrate the region. The European Commission supports its efforts through the Africa-EU Strategic Partnerships such as the Africa-EU Migration, Mobility and Employment Partnership, the Science, Information Society and Space Partnership and the Joint Africa-EU Strategy Action Plan ((JAES). The Tuning Pilot Project is part of the second Joint Africa-EU Strategy Action Plan 2011-2013. ${ }^{8}$

For the last three decades, various initiatives to foster harmonization of higher education have been launched. The Arusha Convention of $1981^{9}$ is the first and most prominent legal framework for the mutual recognition of degrees and qualifications in higher education in Africa. The Convention, ratified by 19 countries, which took effect in January 1983, is currently undergoing revision under the auspices of the African Union in cooperation with UNESCO. The Convention was meant to serve as the legal framework for the harmonization of higher education in Africa. When it was launched, it was intended to contribute to UNESCO's efforts towards promotion of international academic mobility and facilitate the implementation of some provisions of the charter of the then Organization of African Unity especially in regional co-operation and training of human resources. It was envisioned to promote development and application of knowledge, improve quality of higher education and contribute more effectively to the process of sustainable human development. Although it was ratified by the required number of Member States of the then Organization of the African Unity (OAU), the Convention was never implemented. ${ }^{10}$

${ }^{8}$ European Union Commission and African Union Commission, "Joint Africa-EU Action Plan 2011-2013,” Brussels, Addis Ababa, 2011, http://www.africa-eu-partnership.org/sites/ default/files/doc_jaes_action_plan_2011_13_en.pdf.

${ }^{9}$ Regional Convention on the Recognition of Studies, Certificates, Diplomas, Degrees and other Academic Qualifications in Higher Education in the African States. Adopted at Arusha, 5 December 1981 (UN Treaty Series No. 21522), http://www.unesco.org/education/ studyingabroad/tools/conventions_afr_cover.shtml.

10 Mohamed Chérif Diarra, "Arusha Convention on the Recognition of Studies, Certificates, Diplomas, Degrees and Other Qualifications in Higher Education in African States. Synthesis Report," UNESCO Dakar Regional Office (BREDA), 2011, http://www. adea-wgemps.org/index.php/documents/reports/doc_view/163-arusha-convention-synthesisreport-24-may-2011.html. Paper presented at the workshop "Establishment of a Continental 
In all five African (sub) regions initiatives are under way to promote and strengthen the harmonization and regional integration of higher education coordinated with initiatives and programs for quality enhancement. ${ }^{11}$

At the sub-regional level, the Protocol on Education and Training (1997), signed by 12 member states of the Southern African Development Community (SADC), stands as one instrument meant to achieve harmonisation of the higher education systems in the sub-continent. The main aim of the Protocol is "to progressively achieve equivalence, harmonisation and eventual standardisation of the education and training systems in the region". After ratification by all countries, except Angola, DR Congo and Seychelles, it entered into force in the year 2000. Articles 7 and 8 of this Protocol explicitly refer to the sector of higher education and training, research and development. Article 7 deals with co-operation in higher education and training and clarifies some of the key areas of harmonisation. ${ }^{12}$

A further major regional integration framework forms the East African Common Market Protocol that was signed in 2009 by five head of states of partner states, namely Burundi, Kenya, Rwanda, Tanzania and Uganda. Article 11 of this Protocol deals with the mutual recognition of academic and professional qualifications, experiences obtained, requirements met, licences or certifications granted in other partner states, harmonisation of their curricula, examinations, standards, certification and accreditation of educa-

Accreditation Agency for Higher Education in Africa" African Union Commission, Addis Ababa, 10-11 April 2013; and Juma Shabani. "Quality Regimes in Africa: The Reality and the Aspirations." In Chronicle of African Higher Education, May 2013. Boston: Center for International Higher Education, Boston College, 2013.

11 An overview on the regional endeavours with regard to quality assurance and accreditation of higher education in Africa are given by: Olusola Oyewole, "Harmonisation of Degree Structures, and Regional Qualifications Frameworks in the African Higher Education Space," a paper presented at the COREVIP AAU Conference, Stellenbosch (South Africa), May 30 - June 3, 2011; Olusola Oyewole, "African Harmonisation: An Academic Process for a Political End?" Boston: Center for International Higher Education, Boston College, 2013); Yohannes Woldetensae, "The Overall Landscape of Quality Assurance and Accreditation in Africa," a paper presented at the workshop "Establishment of a Continental Accreditation Agency for Higher Education in Africa", African Union Commission, Addis Ababa, 10-11 April 2013; and Juma Shabani, "Quality Regimes in Africa: The Reality and the Aspirations," in Chronicle of African Higher Education, May 2013, Boston: Center for International Higher Education, Boston College, 2013.

${ }_{12}$ Southern African Development Community (SADC), "Protocol on Education and Training in the Southern African Development Community (SADC)," 1997, http://www sadc. int/files/3813/5292/8362/Protocol_on_Education__Training1997.pdf; and Karola Hahn. "Towards a SADC Area of Higher Education. Namibian Economy Policy Research Unit. NEPRU Research Report No. 30," Windhoek: Namibian Economic Policy Research Unit (NEPRU), 2005. 
tional and training institutions for the purpose of free movement of labour within the region. ${ }^{13}$ Higher education in the region is expected to play a vital role in the production of qualified labour force to spearhead the much anticipated growth and development.

In addition to this Protocol, three members of the East African National Regulatory Agencies for higher education, namely the Commission for Higher Education in Kenya, Tanzania Commission for Universities, and National Council for Higher Education, Uganda, signed a Memorandum of Cooperation in 2006. The Memorandum of Cooperation outlined key areas of mutual concern such as developing common criteria, benchmarks and frameworks for quality assurance, credit accumulation and transfer system, and framework for describing and quantifying the content of study programmes to standardize the process of equating and recognizing qualifications. The Memorandum of Cooperation led to the establishment of the Inter-University Council for East Africa (IUCEA), a regional university association which has developed into a key driver of the regional integration process of higher education in Eastern Africa. ${ }^{14}$

In Western Africa, the ECOWAS education sector policy was developed in 2002 based on a Protocol on Education and Training and a General Convention on the Recognition and Equivalence of Degrees, Diplomas, Certificates and Other Qualifications in ECOWAS Member States. The Convention seeks to promote the recognition of qualification through a set of accepted uniform criteria for assessment for the member states to develop the human resources necessary in the region and to reduce brain drain and to facilitate the exchange of skills and the pursuits of studies. ${ }^{15}$

The regional integration and harmonization processes are now guided by the ECOWAS Vision 2020 which was adopted in 2008. In the Strategic Plan, higher education is regarded as important tool to produce the labor force

${ }^{13}$ East African Community (EAC), "Protocol on the Establishment of the East African Community Common Market," Intergovernmental Agreement, Arusha: EAC, 2009, http:// www.commonmarket.eac.int/documentation/doc_view/48-common-market-protocol. raw?tmpl=component.

14 Tuning Africa, "Feasibility Study into the Relevance of a Tuning Approach for Higher Education in Africa. Final Report. April 2011," Tuning Africa, 2011, http://www.tuningafrica. org/index.php?option=com_content\&view=article \&id=2\&Itemid=105\&lang=en; InterUniversity Council for East Africa (IUCEA). http://www.iucea.org/.

${ }^{15}$ Economic Community of West African States (ECOWAS), "Regional Convention on the Recognition and Equivalence of Qualifications," 2002, http://www.comm.ecowas.int/dept/ stand.php?id=e_e1_brief; ECOWAS, “Strategic Plan 2011-2015," Abuja: ECOWAS Commission, 2010. http://www.spu.ecowas.int/wp-content/uploads/2010/06/REGIONALSTRATEGIC-PLAN-RFV-in-English.pdf. 
needed to ensure the competitiveness of the ECOWAS region, hence a the explicit link of higher education to the socio-economic needs and labour market of the region. ${ }^{16}$

Initiatives of harmonization in higher education are also underway in the Arab countries of Africa however not limited to the African Arab countries but encompassing the entire Arab Region beyond continental borders. The Association of Arab Universities (AArU), founded in 1964 is an organization working within the framework of the Arab League striving to support and connect universities in the Arab world, and to enhance cooperation among them..$^{17}$

A further prominent initiative in the Northern African Region is the Arab Network for Quality Assurance in Higher Education (ANQAHE). ANQAHE was established in 2007 as a regional network to coordinate and boost higher education quality assurance efforts. It comprises eleven Quality Assurance Agencies as full members and five further Quality Assurance Entities as Associate members from sixteen Arab countries. African members are Libya, Egypt, Sudan and Eritrea as well as Morocco and Tunisia. ANQAHE is active in the area of quality standard development, awareness raising for a quality culture and quality management, capacity building in quality assurance through distance education, policy dialogue, development of a regional qualification framework (Arab Generic Qualification Framework), dissemination of best practices and research on quality assurance in the region. ${ }^{18}$

With regard to the francophone Africa, the "Conseil Africain et Malgache pour l'Enseignement Superieur", CAMES, is the key driver of harmonization and quality assurance in higher education. The organization which was established in 1968 is promoting the alignment of programmes in its 19 member states. Since 2005, one of its overarching objectives is the structural harmonization of seven francophone degrees ${ }^{19}$ to the "Licence-MasterDoctorat" (LMD) reform in line with the Bologna process. "However, implementation of this reform faces some challenges mainly due to lack of national quality assurance agencies to accredit programmes and maintain a level of quality that meets regional and international standards." 20

16 Ibid.

17 Association of Arab Universities (AARU), http://www.aaru.edu.jo/.

18 Arab Network for Quality Assurance in Higher Education (ANQAHE), http://www. anqahe.org/.

19 (1) Diplôme d'études Générales, (2) Licence, (3) Maîtrise, (4) Diplôme d'études approfondies, (5) Doctorat de troisième cycle, (6) Doctorat unique and (7) Doctorat d'Etat.

20 Juma Shabani, "Quality Regimes in Africa," 1. 


\section{From Feasibility Study to the Tuning Africa Pilot Project}

At a political level, the experiences of the Tuning approach in Europe and other world regions were contemplated as instrument to foster regional integration of higher education in Africa. The African Union Commission supported a European Union commissioned Tuning Africa Feasibility Study in 2010 to explore the relevance, appropriateness, and the eventual scale of the initiative to support the African harmonization strategy. The study was commissioned by the European Commission within the broader context of joint African-EU policy for the development of Higher Education in Africa and in response to a recommendation from the Conference "Developing Links: EU/Africa Cooperation in Higher Education through Mobility" in December 2008. ${ }^{21}$

The Tuning Africa Feasibility Study has shown the Tuning approach to be an important tool for harmonization in terms of its relevance, appropriateness and timeliness for the continent. The effort is recognized as complementing and strengthening existing regional initiatives as well as the efforts of professional associations and academic networks. What is particular about Tuning is that it is a bottom-up approach driven by academics directly involved in the development of curriculum and programs. The Tuning exercise enhances a sense of ownership of the process by academics, promotes the exchange of good practices with peers across borders, and fosters staff collaboration on curriculum development and other initiatives - in the process contributing to networking and capacity building.

The timeliness of a Tuning Pilot Project is not only seen in the political context of regional integration but also in its significance to the rapid expansion of higher education, its quality gaps, relevance of curricula and employability of graduates. Moreover, the signature participative approach that attracts various stakeholders fosters revitalizing curricula, provides a thorough understanding of curricula at subject level and facilitates the intracontinental student mobility by bridging gaps between disparate educational systems. The joint bottom-up dialogue on curriculum development and on the formulation of common points of reference made possible an in-depth reflection on methods of teaching, learning and assessment as well as effective quality management.

The Feasibility Study also considered distance education - a pioneering approach in the Tuning initiative. This is largely because distance education

${ }^{21}$ Tuning Africa, "Feasibility Study," 3. 
has been presumed to play an important role in addressing the insatiable appetite for higher education in the region. The special characteristics of distance education-catering to students in the peripheries or remote areas, professional development and, lifelong learning-have been considered instrumental.

The Feasibility Study concluded that "Tuning" is consistent and coherent with the overarching policy framework of the African Union Harmonization Strategy and numerous existing regional initiatives in higher education reform, quality assurance, standard setting and recognition such as national qualification frameworks, regional qualification frameworks, and the Arusha Convention. Furthermore, it was described as contributing to providing the platform for dialogue and encouraging regional, inter-regional and intercontinental networks of institutions and academics.

Unlike other initiatives which tend to be exclusively a top-down or bottom-up approach, the Tuning process is a dual mode interaction that combines top-down and bottom-up approaches providing a dialogue platform where academics play the prominent roles. The adaptive and consultative features of the Tuning approach seem ideal in promoting the sector-crossing dialogue needed to implement espoused policies and strategies.

Based on a consultative process that comprised numerous relevant African stakeholders, the African Union Commission decided in March 2011 to test the Tuning approach as potential instrument in the implementation of the Harmonization Strategy. In a validation workshop with various stakeholder organizations of the higher education sector in Africa held in Nairobi in March 2011, five priority areas were identified for the pilot project that comprised Agricultural Sciences, Civil and Mechanical Engineering, Medicine and Teacher Education.

A call for participation in the "Harmonisation and Tuning African Higher Education" project was launched in October 2011. In November 2011, a selection workshop was held in Dakar, Senegal, followed by an international conference entitled "Tuning, Credits, Learning Outcomes and Quality: A Contribution to Harmonisation and the Space for Higher Education in Africa". The forum brought together prominent regional higher education associations, quality assurance bodies and higher education officials.

The selection workshop screened 96 applications. Ethiopia submitted the largest number of applications (9) followed by Nigeria and Kenya (each 7). The largest application was in Agricultural Sciences (24) followed by Teacher Education (22). Others include Mechanical Engineering and Civil Engineering 9 applications each; Medicine 10. In total, 74 applications were considered for participation in the Tuning pilot project. 
The selection for the Tuning Africa Pilot Project was based on the following criteria:

1. Demonstration of national excellence in the subject areas including innovation, teaching and learning, employability, linkages between research and teaching, cooperation with industry;

2. Participation in collaborative networking and capacity for dialogue with other institutions working on the same subject area;

3. Demonstrable evidence to contribute to the development of higher education in the country and region;

4. Commitment to implement the outcomes of the pilot project;

5. Experience in distance learning;

6. National and regional balance of the institutions applying, including type of institutions (e.g. institutions from urban and rural areas).

A commitment letter from the leadership of the university was one of the pre-requisites for eligibility to participate in the pilot project so as to ensure the ownership and a sustainable impact of the pilot project at institutional level. As not all short-listed universities were finally selected, further recruitment efforts were made to reach $60-$ the designated number of potential participants for the pilot phase.

\section{The Pilot Project: Relevant Subject-Areas}

The Tuning Africa participants agreed that the Pilot Project focus on five subject/thematic areas of relevance for Africa. It was discussed whether the choice of subjects follow along the lines adopted by the Pan African University (PAU). ${ }^{22}$ As PAU is targeting the postgraduate level, it was agreed not to adopt this framework but instead develop a new one targeting five specific subject areas "allocated" to five regions.

22 The Pan African University is an initiative of the African Union Commission to revitalize higher education and research in Africa. It is conceptualised as a network university based on five thematic regional hubs providing graduate education on Master and doctoral level and engaging in research in areas relevant for the development of the continent. Four of the five hubs are in a planning stage; three of them started first academic operation late 2012 and beginning 2013. See also Damtew Teferra, "Pan African University: Rescuing the Vision" International Network for Higher Education in Africa (INHEA) Editorial Series (June 2012), Boston: Center for International Higher Education, Boston College, 2012, https:/htmldbprod. bc.edu/prd/f?p=2290:4:0::NO:RP,4:P0_CONTENT_ID:118382. 


\section{Table 1}

Overview Participation and Scope of the "Tuning Africa" Pilot Project

\begin{tabular}{|l|l|c|}
\hline \multicolumn{1}{|c|}{ Subject Area } & $\begin{array}{l}\text { Lead Managing Country of } \\
\text { SAG (Subject Area Group) }\end{array}$ & $\begin{array}{c}\text { Number of African } \\
\text { Countries Participating in } \\
\text { the Pilot Group }\end{array}$ \\
\hline Agriculture & Nigeria & 12 \\
\hline Civil Engineering & Ethiopia & 10 \\
\hline Mechanical Engineering & Cameroun & 12 \\
\hline Medicine & Egypt & 10 \\
\hline Teacher Education & South Africa & 13 \\
\hline
\end{tabular}

Two engineering disciplines were selected to address the continent's huge needs in these fields. It was also noted that these fields promote sustainable development through science and technology education. Each of the subject areas was attributed to one region. The lead university of each selected subject area coordinated a network of ca. 10 universities participating in the subject area group (SAG). In total 57 African universities participated in the pioneering exercise. The SAG held four meetings in the following venues:

1. Yaoundé, Cameroun: 23-25 January 2012

2. Cape Town, South Africa: 15-18 May 2012

3. Brussels, Belgium: 18-22 November 2012

4. Nairobi, Kenya: 21-24 January 2013

Teacher Education was mentioned in all African regions as a prime area of concern. Teacher Education is considered a core challenge on all system levels of education, in particular in science and technology and increasingly also with regard to Technical and Vocational Education (TVE) which is likely to assume greater prominence in the future, as the training needs of the young is soaring.

Agriculture continues to play a critical role in most African countries as it continues to be a source of livelihood. Its significance is prominent at the region is grappling with food security and development. It remains an important foreign exchange earner in the continent and provides the raw materials for numerous industrial processes. In Africa, the agricultural sector is still the core sector and employs 65 per cent of the labour force and accounts for 32 percent of gross domestic product (GDP). ${ }^{23}$

${ }^{23}$ World Bank (WB), "Fact Sheet. The World Bank and Agriculture in Africa," 2013, http://web.worldbank.org/WBSITE/EXTERNAL/COUNTRIES/AFRICAEXT/0,,contentMD $\mathrm{K}: 21935583 \sim$ pagePK:146736 piPK:146830 theSitePK:258644,00 html. 
The management and technological developments in the agricultural sector are lagging behind the needs of the continent; and higher education is expected to play an important role in enhancing agriculture reforms. And yet graduates from Agriculture seem to lack the requisite knowledge and appropriate competences needed for meaningful impact on the modernization of agriculture.

Civil Engineering was selected as one of the programs for the Tuning Pilot Project due to the fact that urbanization is a growing African phenomenon as the region's population is rapidly growing. This has been a constant concern for governments and development agencies. In 2030, half of the African population will live in cities. According to a recent report by UNHABITAT, the United Nations Agency for Human Settlements, the population of some cities is set to swell by up to 85 per cent in the next 15 years. The most populous city in 2010, Cairo, will grow by 23 per cent to 13.5 million people. By 2025, however, it will have been overtaken by both Lagos (15.8 million) and Kinshasa (15 million). Food and water shortages, poor infrastructure and a lack of housing will remain outstanding problems during such rapid urbanization. ${ }^{24}$

This demographic development has a deep impact on energy, water, and the climate. The built environment will need to grow exponentially. Infrastructure such as housing and informal settlements, social infrastructure (schools, hospitals, kindergartens, sanitation facilities, recreation centers, sport facilities) will be needed for millions of inhabitants. New waste and water management systems will be needed. Construction need to increase with regard to traffic and transport (roads, bridges, railways, and airports), industrial buildings, plants and production, processing and storage facilities as well as social and urban spaces. Hence the need for abundant and competent civil engineers to guide, build and support this mammoth construction needs is palpable.

The number of engineering graduates in Africa is lagging far behind the international norms. For many years there have been relatively small and few mechanical engineering programmes in African universities but in recent years the numbers are increasing, albeit, slowly. There appears to be an interesting confluence of efforts in African universities to boost the number of mechanical engineering graduates either through increasing the number of universities offering such programmes or increasing the intake into existing mechanical engineering programmes. This signals progress and highlights the need to restructure mechanical engineering programmes and their

${ }^{24}$ Economist, 13 December 2010. 
curricula to meet future challenges and generate graduates with the knowledge and competences required.

Many African countries have formulated development and transformation plans based on the promotion of science and technology to boost industrial growth and social well-being. Mechanical Engineering is thus perceived as a crucial discipline to provide the qualified labour force needed for industrial development, which was the main rationale to include it into the Tuning Pilot Project.

In some countries, Mechanical Engineering - as the core engineering discipline - is emerging as a new field of study. For example, in Ghana only one university offered Mechanical Engineering at the degree level for over 40 years; but now, in Zambia and Egypt, there are three. In Namibia, the University of Namibia is building its first Faculty of Engineering in the North. As part of massive expansion and reform, Ethiopia has targeted an enrolment rate of 70 per cent in Engineering and 30 per cent in Humanities as it is establishing 10 institutes of technologies.

Only few African countries such as Egypt and South Africa generate a relatively high number of engineering bachelors per capita-approaching the level of USA and Germany. However, South Africa still plans to boost the numbers of engineering graduates and nearly double them up to 15,000 by 2014. In 2009 it granted 1,459 Mechanical Engineering degrees at the BSc level in addition to 111 at the postgraduate level. ${ }^{25}$

Some of the disciplines in the pilot project are highly regulated study programs with many stakeholders playing a crucial role. This refers to Medicine, Teacher Education, and Civil Engineering. Ministries, state and quality assurance agencies as well as professional associations and lobbyists from industry regulate and/or influence standards and access to professional pathways. This meant that the autonomy and academic freedom of institutions needed to be moderated in reforming curricula as they were to be closely coordinated with a host of different agencies. This thus makes curricular reform efforts in professional academic programs slightly more cumbersome, if not challenging.

The institutional stakeholder landscape of Civil Engineering in two African countries is given below, in order to illustrate the complexity of meaningful higher education reforms in the respective field and highlight the importance of integrating stakeholders in the reform process.

${ }^{25}$ Tuning Africa, "Presentation of Final Report of 5 Subject Areas. Final Report 20112013." Paper presented at the Joint Africa-EU Strategy Tuning Seminars, Nairobi, 23 January 2013. http://www.tuningafrica.org/images/stories/documentos/sag_presentation_nairobi_ january\%202013.pdf. 


\section{Table 2}

\section{Institutional Stakeholder Landscape of Civil Engineering in Ethiopia and South Africa}

\begin{tabular}{|c|c|}
\hline Ethiopia & South Africa \\
\hline $\begin{array}{l}\text { Adama University of Science and } \\
\text { Technology } \\
\text { Addis Ababa Institute of Technology } \\
\text { (AAiT), Ethiopian Institute of } \\
\text { Architecture, Building Construction and } \\
\text { City Development (EiABC) - both Addis } \\
\text { Ababa University } \\
\text { Association of Construction Technology } \\
\text { and Management } \\
\text { Association of Ethiopian Architects } \\
\text { Consultant and Practicing Engineers } \\
\text { Engineering Capacity Building Programme } \\
\text { (ecbp) - Bilateral Ethio-German reform } \\
\text { programme } \\
\text { Ethiopian Railway Authority } \\
\text { Ethiopian Roads Authority } \\
\text { Ethiopian Society of Engineers } \\
\text { Ethiopian Society of Water Resource } \\
\text { Gondar University } \\
\text { Haramaya University } \\
\text { Hawassa University } \\
\text { Higher Education Relevance and Quality } \\
\text { Agency (HERQA) } \\
\text { Higher Education Strategy Center (HESC) } \\
\text { Jimma University (JU) } \\
\text { Mekelle Institute of Technology (M-EiT) - } \\
\text { Mekelle University } \\
\text { Ministry of Education } \\
\text { Ministry of Housing } \\
\text { Ministry of Science \& Technology } \\
\text { Ministry of Urban Development and } \\
\text { Construction } \\
\text { Ministry of Water and Energy } \\
\text { Ministry of Water Works } \\
\text { Student Council }\end{array}$ & 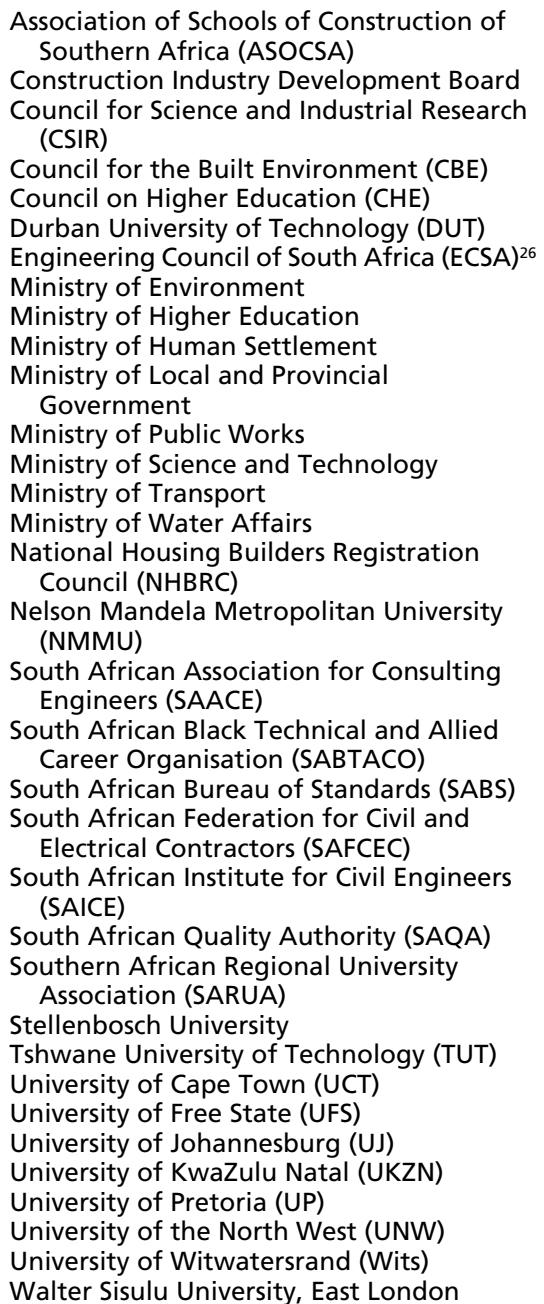 \\
\hline
\end{tabular}

${ }^{26}$ ECSA is a statutory council which is inter alia responsible for the registration of professional engineers and for the accreditation of the academic programmes for engineers at South African universities. 


\section{Generic Competences in African Higher Education}

The term competence represents a dynamic combination of capabilities, knowledge, understanding, skills and abilities. ${ }^{27}$ Competences are formed in various course units and assessed at different stages. The competences may be differentiated as subject area related competences (specific to the respective field of study) and as well as generic competences (common to any degree course).

Thus, generic competences identify shared elements common to any degree, such as capacity to learn, ability to make decisions, design projects, and skills in interpersonal communication, among others. They are complemented by subject related competences inherent in a degree program which relates to the specific circumstances of a given field of study.

One of the objectives of the Tuning Higher Education in Africa pilot project was to identify generic competences that are relevant to an African graduate - irrespective of the disciplinary or thematic program. The participating subject area groups were therefore requested to identify generic competences that would be expected as learning outcome in their fields of study - as it relates to the African context. The generic competences lists developed by the five subject area groups were thoroughly discussed, analyzed, and integrated. The results of this process were compiled into a list of 18 generic competences as most relevant to higher education graduates in Africa. These are:

1. Ability for conceptual thinking, analysis and synthesis

2. Professionalism, ethical values and commitment to UBUNTU (respect for the well-being and dignity of others) (good will)

3. Capacity for critical evaluation and self-awareness

4. Ability to translate knowledge into practice

5. Objective decision making and practical cost effective problem solving

6. Capacity to use innovative and appropriate technologies

7. Ability to communicate effectively in official/ national and local languages

8. Ability to learn to learn and capacity for lifelong learning (continued development)

9. Flexibility, adaptability and ability to anticipate and respond to new situations

27 Julia González, and Robert Wagenaar, eds., Tuning Educational Structures in Europe. Universities' Contribution to the Bologna Process. An Introduction, 2nd ed. (Bilbao: Universidad de Deusto, 2008). 
10. Ability for creative and innovative thinking

11. Leadership, management and team work skills

12. Communication and interpersonal skills

13. Environmental and economic consciousness

14. Ability to work in an intra and intercultural and/or international context

15. Ability to work independently

16. Ability to evaluate, review and enhance quality

17. Self-confidence, entrepreneurial spirit and skills

18. Commitment to preserve African identity and cultural heritage

Two of the identified generic competences seem unique to Africa as they have not so far appeared in the previous Tuning Higher Education projects in other regions of the world. These are commitment to UBUNTU (respect for the well-being and dignity of others-good will) and commitment to preserve African identity and cultural heritage.

Analysis revealed the following top five generic competences for African higher education in all the identified disciplines:

1. Ability for conceptual thinking, analysis and synthesis

2. Professionalism, ethical values and commitment to UBUNTU

3. Capacity for critical evaluation, and self-awareness

4. Ability to translate knowledge into practice

5. Objective decision making and practical cost effective problem solving

Some subject area groups extended the list of generic competences in the context of the needs of their programs. For example, the Mechanical Engineering Group added the following Generic Competences: Commitment to safety, Ability to negotiate and resolve conflicts, Ability to undertake research at an appropriate level, and Skills in the use of ICT.

\section{Subject-specific Competences in African Bachelor Programs}

After identifying the generic competences, each subject area group went about defining subject specific competences. A general outcome of the Tuning Groups emphasized the need for subject-specific competences that enhance the practice-orientation and relevance of the studies.

The Civil Engineering Working Group identified the subject specific competences in a two-step process. To establish the subject specific competences of a Civil Engineering graduate, the group exhausted the 
requisite skills in the different phases of a civil engineering project. This approach was intended to deliberately link the identified competences to the needs of the labour market and the working environment of civil engineering graduates.

The group has identified six stages in a civil engineering project which it then allocated to the subject specific competences in the different stages of the project. The six project stages include:

1. Conceptualising the construction project (Describing the scope of the project)

2. Viability of the construction project

3. Design and feasibility of the construction project

4. Documentation and procurement

5. Construction (realisation, implementation)

6. Close out of the construction project

Some of the different construction project stages share similar competences which resulted in their duplication. The distinctive 37 subjectspecific competences earlier identified were scaled down to 20 by organizing, systematizing and integration of the competences appropriate in a Civil Engineering program. Finally the subject specific competences were clustered - a first step towards elaborating a meta-profile of the program.

The other subject area groups proceeded accordingly, but rather focusing on the more heterogeneous areas of occupation of the future graduates as not all programs target clearly structured professional processes as Civil Engineering, where a construction project follows very clear standardized steps which require specific competences.

The Tuning Agriculture Group agreed that an African University graduate of Agriculture acquire sixteen subject specific competences on graduation. This includes:

1. Knowledge and understanding of agricultural production, and basic sciences

2. Ability to identify problems and apply knowledge to solving day-today agricultural challenges

3. Ability to evaluate and manage agricultural projects, as well as carry out financial appraisals

4. Entrepreneurial and creative skills

5. Ability to design, plan and implement agricultural research

6. Ability to do business in any part of the world

7. Ability to understand, and adapt to new and emerging technologies in agriculture, including ICT 
8. Ability to implement sustainable practices and technologies for the management of natural resources

9. Ability for independent thinking and be able to work with minimal supervision in the area of agriculture

10. Ability to adapt and transfer technology, as well as be able to create new technologies

11. Ability to know, advice and implement agricultural policies, and regulations

12. Ability to make sustainable use of water and other natural resources for agricultural use

13. Ability to understand and work within the organization, business and community management of the rural sector

14. Ability to identify pests, pathogens, and weeds associated with crops, animals and their products

15. Ability to improve quality and safety along the agricultural value chains

16. Ability to select and manage machinery, implements and equipment for agricultural use in different farming systems

The Teacher Education Group identified four categories of competences: "Knowledge and Understanding", "Practice and Skills", "Values and Ethics", and "Interpersonal skills". A process followed to ensure that the generic competences were captured in each of the four categories and a consensus was established on the following 17 priority competences. ${ }^{28}$

1. Subject knowledge/understanding of the discipline

2. Applying ICTs

3. Developing resources and instructional materials

4. Critical thinking, problem solving, creativity, reflection

5. Ability to assess and evaluate, including self and others

6. Counsel, guide and resolve conflict (peace education) for complex situation

7. Interpret curriculum documents, information and sources, and see them as a roadmap

8. Project management

9. Be able to choose, use and design innovative teaching and learning strategies

${ }^{28}$ Tuning Africa, "Presentation of Final Report of 5 Subject Areas. Final Report 20112013." Paper presented at the Joint Africa-EU Strategy Tuning Seminars, Nairobi, 23 January 2013. http://www.tuningafrica.org/images/stories/documentos/sag_presentation_nairobi_ january\%202013.pdf. 
10. Be able to research (observe, describe, analyse)

11. Understand and apply policies and regulations

12. Ability to identify and deal with students with special needs, gifted and otherwise

13. Ability to work in a team

14. Professionalism, ethics and values: ability to understand and abide by the ethics and values of the teaching profession

15. Ability to become a lifelong learner

16. Ability to develop competencies for employability in students (ability to enhance employability in one's own profession)

17. Ability to inspire self confidence in the learners

As a general frame for a program the SAG Mechanical Engineering identified four major categories: Basic Engineering, Engineering Analysis, Engineering Design, and Engineering Practice. Each category then got populated on relevant requisite knowledge and skills as indicated in the table below.

\section{Table 3}

Outcomes Achieved in the Subject Area Group Mechanical Engineering

\begin{tabular}{|c|c|}
\hline \multirow[t]{9}{*}{$\begin{array}{l}\text { Basic } \\
\text { Engineering }\end{array}$} & $\begin{array}{l}\text { The ability to demonstrate knowledge and understanding of } \\
\text { the basics of: }\end{array}$ \\
\hline & $\begin{array}{l}\text { Mathematics including differential equation, integral calculus, } \\
\text { linear algebra, vector algebra, numerical methods, probability } \\
\text { and statistics }\end{array}$ \\
\hline & High-level programming \\
\hline & Solid and fluid mechanics, statics and dynamics \\
\hline & Material science engineering, and strength of materials \\
\hline & Thermal science: thermodynamics and heat and mass transfer \\
\hline & $\begin{array}{l}\text { Principles of turbo-machinery, reciprocating engines and } \\
\text { machines, and material handling equipment. }\end{array}$ \\
\hline & Electrical and electronic circuits, electrical machines and drives \\
\hline & Control systems \\
\hline
\end{tabular}




\section{Table 3}

Outcomes Achieved in the Subject Area Group Mechanical Engineering (continued)

\begin{tabular}{|c|c|}
\hline \multirow{4}{*}{$\begin{array}{l}\text { Engineering } \\
\text { Analysis }\end{array}$} & The ability to analyse: \\
\hline & Mass, momentum and energy balances and efficiency of systems \\
\hline & Hydraulic and pneumatic systems \\
\hline & Machine elements and mechanical systems \\
\hline $\begin{array}{l}\text { Engineering } \\
\text { Design }\end{array}$ & $\begin{array}{l}\text { The ability to carry out design of machine elements and } \\
\text { mechanical systems using both traditional means and } \\
\text { computer-aided tools }\end{array}$ \\
\hline \multirow[t]{4}{*}{$\begin{array}{l}\text { Engineering } \\
\text { Practice }\end{array}$} & $\begin{array}{l}\text { The ability to demonstrate the safe use of workshop and } \\
\text { laboratory equipment }\end{array}$ \\
\hline & $\begin{array}{l}\text { The ability to operate and maintain mechanical equipment and } \\
\text { systems }\end{array}$ \\
\hline & Understand and apply safe systems, codes and standards at work \\
\hline & The ability to select and use control and production systems \\
\hline
\end{tabular}

\section{Competences: Importance, Achievements and Ranking}

As part of the Tuning Methodology set of instruments, a survey was conducted by all five subject area groups in all participating countries. The objective of the survey was not only to raise data but to also initiate a dialogue on institutional, subject area (discipline) and general level. The total number of respondents of the five subject areas considered was 4323 distributed across four stakeholder groups as such: Students (1304), Academics (1130), Graduates (1051) and Employers (838).

The consultative survey results were subjected to a host of analysis according to their importance, ranking and actual achievement-in the different subject area groups. In general, there was a correlation in all stakeholder groups and subjects regarding the discrepancy of the importance of competences and their achievement.

The Academics stated a discrepancy - shared in all subject groups - with regard to ranking and achievement in the following two competencies: Ability for creative and innovative thinking as well as Professionalism, ethical values and commitment to UBUNTU. The Employers generally rated the achievement of all generic competences much lower than their importance - which clearly indicates an employability-oriented reform need of the 
programs. Employers in particular experience a huge gap between importance and achievement with regard to the following competences: Ability to transfer knowledge into practice, Ability for creative and innovative thinking as well as Objective decision making and practical cost effective problem solving. Students recognized a strong correlation of importance and underachievement with regard to the generic competences. The students identified the highest discrepancy with regard to the Capacity to use innovative and appropriate technologies. ${ }^{29}$

All stakeholder groups identified the most important competences as the Ability to transfer knowledge into practice as well as Ability for conceptual thinking, analysis and synthesis. The other competences in the top five ranking however varied. All groups ranked the following competences as less important: Ability to work in an intra- and intercultural and/or international contexts, Environmental and economic consciousness, and Commitment to preserve and to add value to the African identity and cultural heritage.

There was a commonly shared understanding in all status groups that the highest achievement was an Ability to communicate effectively in officiall national and local language and in the Ability to work independently. The employers ranked Leadership, management and team work skills much higher than the academics.

The results of the Mechanical Engineering Group on the generic competencies, for instance, yielded a number of important general observations: The levels of importance and corresponding levels of achievement for each competence identified the current gaps. Levels of importance were much higher than levels of achievement. The majority of the proposed generic competences was considered highly important by most stakeholders. Furthermore, general agreement, among the various stakeholder groups on the ranking of the common generic competencies, was evident.

The highest gaps between importance and achievement levels were identified in competencies related to the Ability to use innovative technologies, Ability for creative and innovative thinking and self-confidence and Entrepreneurial skills. Competencies related to environmental and economic consciousness, to the preservation of African cultural heritage, and the ability to work in regional and international contexts were placed at the bottom of importance and ranking lists by all groups.

${ }^{29}$ Pablo Beneitone, "Generic Competences: Consultation with Stakeholders in Africa. Some Results and a Comparison with Other Regions," a paper presented at the Joint AfricaEU Strategy Tuning Seminar, Cape Town, 15 May 2012, http://www.tuningafrica.org/images/ stories/documentos/africa_presentacion_cape_town_pablo_2012_generic_competences.pdf. 
The Tuning Agriculture Group identified a high correlation between academics and employers in all aspects which may be interpreted as an outcome of a close cooperation and communication between the academic and the labour sector. There is considerable agreement in the top five rankings stated above. All the stakeholders, except the graduates, considered Sound knowledge and understanding of agricultural production, and basic sciences as the first priority competence for agriculture graduates. This was closely followed by Ability to identify problems and Apply knowledge to solving dayto-day agricultural challenges, which was however ranked first by graduates.

All the stakeholders are in close agreement that agricultural graduates should be able to design, plan and implement agricultural research and this was ranked as either third or fourth in the list of priorities. The ability to possess entrepreneurial and creative skills was ranked third by employers and graduates, fourth by academics and fifth by students. Ability to evaluate and manage agricultural projects, as well as Ability to carry out financial appraisals were ranked fifth by academics and employers and four by students respectively.

The analyses of the Civil Engineering Programs identified the following generic competency gaps missing completely (or only partially featured) in existing curriculum and was concluded as not leading the graduate to the expected learning outcomes. A need for fostering the following competences in the Civil Engineering Programs in Africa became evident in the following areas:

1. Capacity to use innovative and appropriate technologies

2. Commitment to preserve and to add value to the African identity and cultural heritage

3. Environmental and economic consciousness

4. Self-confidence, entrepreneurial spirit and skills

5. Professionalism, ethical values and commitment to UBUNTU

In Civil Engineering, the competences with the largest gaps between the achievement in the curriculum and the importance are valued with high importance. These competences seem to be quite challenging to transfer to students. Hence, further discussions were recommended on how to integrate these competences into the curriculum and how teach and assess them.

The analysis of the subject specific competences in Civil Engineering revealed the following five competences with gaps regarding the achievement in the curriculum and their importance:

1. Ability to program (to plan the process and allocate resources)

2. Commitment to health and safety 
3. Capacity to introduce health and safety measures in construction and materials

4. Skills to deal with dispute resolutions

5. Skills in commissioning

It was considered that these gaps may have been the result of contents not being taught at university level where the greatest proportion of the time is spent on educating students in how to design and analyse problems from a mathematical point of view. The overall tendency is to teach mathematics and science skills at the university level and relegate the rest, such as programming, health and safety, dispute resolutions and commissioning skills, to graduates workplace for development in the earlier years of their professional life. It is also posited that the competence gaps may have been the matter inherent in Construction Technology and Management Programs than in Civil Engineering Programs.

It is true that the mentioned competences may be acquired as on-site aspects, hands-on courses or extra courses offered by employers, and thus can be add-ons (electives) in the core curriculum. The competences may not be part of a program as they may have financial implications for the employers, for instance on matters of safety and health. The Civil Engineering group supports the idea of integrating Health, safety and security into Environmental Impact Assessment methodology and frameworks. However, it is presumed that legal and regulating frameworks set by governing bodies may leave little room for manoeuver.

The wide consultations with different stakeholders indicate a big discrepancy between what stakeholders considered "important" and what is actually "achieved" in the educational delivery. Most typically, the Abilities of conceptual thinking, analysis and synthesis as well as the Translation of knowledge into practice seem to be commonly shared gaps across all subject area groups.

The survey by the Medicine subject area group identified a huge gap between the top five competences agreed upon and their achievement. Achievement is consistently given a lower rating than the importance attached to it in three areas of concern:

1. Teamwork - leadership - management

2. Professionalism

3. Effective and sensitive communication

The Teacher Education Group identified a large gap with regard to the Ability to develop own and learners' entrepreneurial skills. All groups shared the same opinion. There seem to be substantial gaps in Teacher 
Education programs in the instructional service delivery. The respondents singled out Professionalism, ethics and values, Ability to understand and abide by the ethics values of the teaching profession and Develop own and learners' entrepreneurial skills as poorly achieved; and yet these are some of the most important competences a teacher is expected to possess. One of the most striking revelations of the findings was the rating of academics on competence to develop own and learner's entrepreneurial skills as the least importance and least achieved. ${ }^{30}$

The comparison of results between the Tuning Europe, Tuning Latin America and the Tuning Africa projects showed a commonality of the top two competences. These are Ability to translate knowledge into practice and Ability for conceptual thinking, analysis and synthesis. ${ }^{31}$

\section{Meta-Profiles of Programs: Similarities, Discrepancies and Reform Needs}

An analysis of the generic and subject specific competences in each subject area group as well as the analyses of the questionnaires with regard to "importance", "achievements" and "ranking" of competences led to the development of a so-called meta-profile of each program. The meta-profiles represent the main structural elements: the core content thematic areas combined or clustered with the generic and subject specific competences which give a program its specific identity. The meta-profiles of the subject areas of the Tuning pilot project were developed by each group as referential elements (points of reference) for further dialogue and reflection and analysis of possible classifications (clusters).

The experiences in the development of the meta-profiles of the programs indicated major differences in specific subject areas. The required knowledge in Civil Engineering is generally taught in the following core clusters: design and analysis, construction and project management. The Civil Engineering group concurred on the following distribution of the curriculum: Design and analysis 80 per cent, Construction 10 per cent and Project management a further 10 per cent. This distribution predicates on most universities offering separate degrees in Construction Management and therefore the knowledge that the Civil Engineering students need is seen as

${ }^{30}$ Tuning Africa, "Final Report of Teacher Education." Paper presented at the Joint Africa-EU Strategy Tuning Seminars. Fourth General Meeting, Nairobi, 23-25 January 2013. http://www.tuningafrica.org/images/stories/documentos/booklet_nairobi_ingles_subir.pdf.

${ }^{31}$ See also Beneitone, "Generic competences." 
basic knowledge in that particular field. The same is considered to apply to project management. In generating the meta-profile, the Civil Engineering group clustered the 18 generic competences into the following areas: Critical thinking, Professionalism, Creativity, Communication, Leadership, and Regulation.

The Tuning Agriculture Group clustered the competences around the following core categories: Learning process, Social values, Innovation, Organization and Communication skills, Technical and technological capacity. The comparison with existing programs revealed that the main aspects were represented in all programs, though some elements of the ideal meta-profile, such as Entrepreneurial and creative skills, needed further discussion on the teaching and learning process. Also the communication of the agricultural professionals with other professionals or the respective stakeholder (as farmers) in different languages (e.g. in multi-language cultures/regions/countries) was perceived as challenging. In this group, several suggestions were made to guide future reforms including bringing trainees in direct contact with farmers, ensuring good practical content in agricultural programs, integrating a research work and writing a thesis in the final year of studies, as well as the training of newly recruited lecturers in pedagogy as a preparation for teaching.

The Tuning Medicine Group agreed that the detailed curriculum in Medicine may vary from institution to institution, and between regions and countries. However, it stressed that the competences of a graduate in Medicine remain effectively universal. Consequently all graduates in Medicine must be expected to have achieved an effective competence in each of the core areas of the subject (see below). At the same time, the group recognized Medicine as a highly dynamic subject with the curriculum constantly requiring review, update and revision to cope with contemporary social, economic and scientific needs as deemed by changing contexts and challenges.

As an outcome of the survey and consultation process, the Medicine group explored the potential architecture for a profile of a medical graduate in Africa and identified clusters of skills and competences following intensive transnational and trans-language working groups, i.e. mixing Francophone and Anglophone. The group adopted a concept of 'pillars' to describe the critical support and architectural components in a general medicine education and identified seven 'pillars' which provide the basis for the meta-profile of a Medical graduate. These include Clinical expertise and knowledge, Community and environmental health focus, Professionalism, Effective and sensitive communication, Teamwork/leadership management, Engagement in a learning journey, Continuing professional development as well as Adaptability to ICT and new technology. 
Within these seven 'pillars' the group highlighted specific African features. Hence a 'Community and environmental health focus' is considered to be particularly relevant for African graduates. This is predicated on preparing medical students for the challenging urban and rural African contexts which demand special skills to serve diverse communities.

Similarly 'Effective and sensitive communication', has received particular resonance in recognition of the wide language, educational, social, economic and cultural differences that exist across the continent. Communication in many African countries can present challenges because of the number and variety of languages spoken in Africa. This thus entails that the medical practitioner needs to be particularly thoughtful about the way in which information is conveyed and processed. 'Adaptability to ICT and new technology' involves not simply the need to be competent in the recent innovations but also recognition of the variety of practical challenges in rural and urban contexts in Africa.

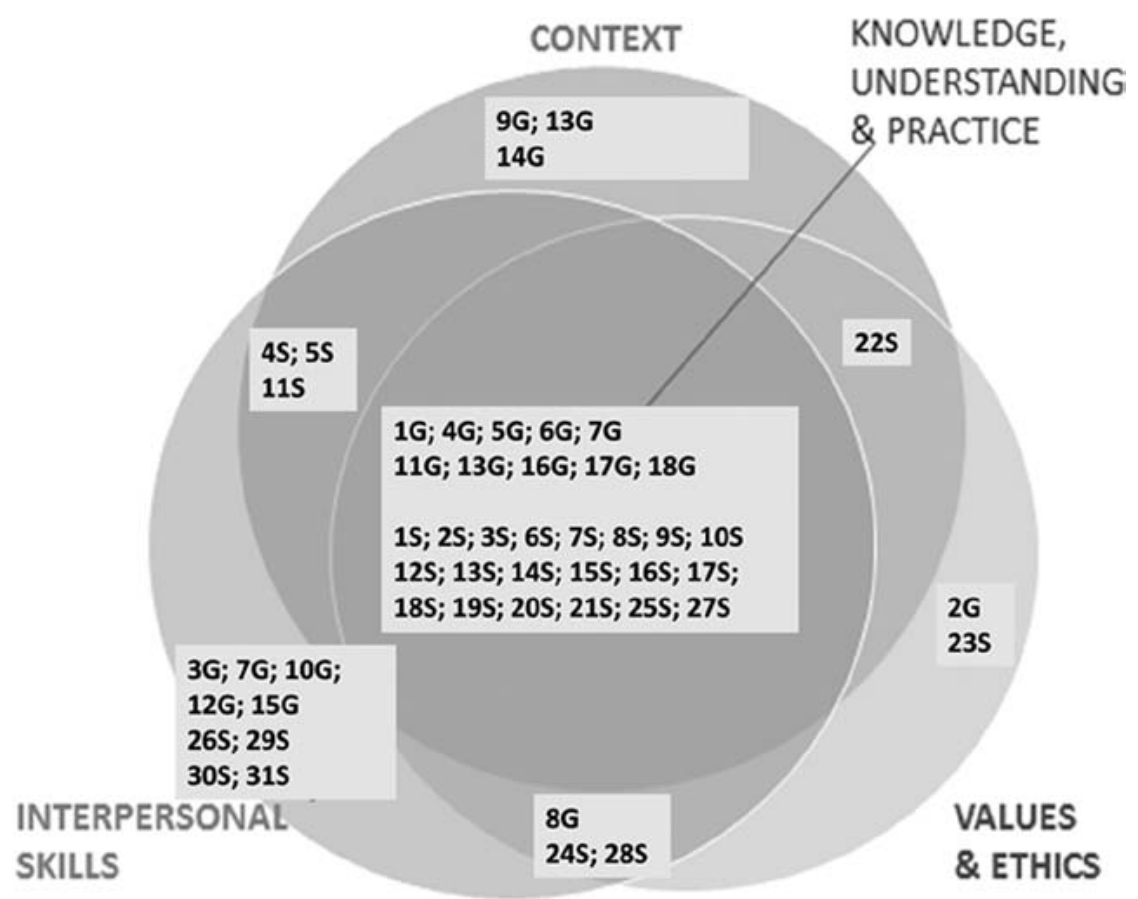

Figure 1

Teacher Education Subject Group “ideal” meta-profile. 
While the concept of 'pillars' provides a valuable starting point for establishing the profile of a graduate in Medicine in Africa, it was not felt to reflect either the complexity or the integrated nature of the requirements for a medical graduate that combines academic knowledge and strong understanding of technical competences. All the skills and competences are considered essential and interdependent. Consequently the group sought to represent this in an integrated way with clinical expertise and knowledge at the core. A general concern was raised by the Medicine Group which pointed to insufficient or nonexistent assessment of the competences within the meta-profile of the programs.

The Teacher Education Subject Area Group visualized the "ideal" metaprofile in a Venn diagram. The diagram shows the interconnectedness of the four reference clusters (Context, Knowledge/Understanding and Practice, Interpersonal Skills, and Values and Ethics) and how both, the specific and generic competences are spread across the integrated referential points: "G" refers to the "generic competences" developed by the entire Tuning group listed in Chapter 6 of this article; "S" refers to the Teacher Education specific competences. A list of these 31 subject-specific competences identified by the SAG Teacher Education can be found in the annex of this article.

The diagram shows that some generic and some subject specific competences are related to all four clusters. However, the ideal meta-profile of Teacher Education Programs should not lead to the conclusion of a prior presence of uniformity. The Teacher Education programmes in Africa seem to be very diverse - even within one and the same country. The intracountry diversity however was reduced in some countries with the introduction of regulatory bodies.

\section{Conclusion: Lessons of Experience and Way Forward}

The Harmonization and Tuning Higher Education in Africa Pilot Project, an initiative of the African Union Commission and the European Commission has had outcomes of political as well as academic dimensions. Its political impact became visible on different system levels: Continental, regional and national levels. It revitalized the debate on harmonization and raised awareness with regard to the need for curricula reform and quality management as pre-requisite for the achievement of the continental development goals. It stimulated discussions of the intermediary bodies in higher education and it provided an opportunity for close dialogue with professional associations, future employers in the private and public sector.

On the academic dimension, it provided a unique opportunity for 57 African universities, their academic staff, academic administrative officers 
(e.g. quality managers, curriculum developers) and the university leadership to discuss across borders on teaching and learning, programs, degree profiles and degrees, the enhancement of quality and credits in their specific disciplines. The Tuning Project hence has created an opportunity for a meaningful dialogue and networking with often delinked stakeholders and isolated debates.

The Tuning group has jointly developed an improved understanding of a graduate's competences that are relevant to a variety of scopes, prominently to the labour market, and thus perceived the reform project as a step towards closing the gap between higher education and the continent's needs. The networking opportunities created by the exercise and the success in achieving a common language and conception with regard to curricula reform can thus be perceived as a small, but relevant step towards harmonization in higher education and the creation of an African academic identity and understanding.

The main achievement of the Tuning Africa pilot project was the development of conceptual frameworks and frames of reference for degree programs in thematic core areas for the sustainable development of Africa, namely in Medicine, Agriculture, Teacher Education, Civil and Mechanical Engineering. The developed academic and professional meta-profiles of the respective programs - based on jointly developed sets of generic competences and catalogues of subject specific competences - are anticipated to ensure a successful integration of a graduate into the African labour market.

The incorporation of distance education into the Tuning methodology was a pioneering experience for the Tuning Team; and it is anticipated that it will enrich the Tuning projects in other regions of the world. It should be however clear that a competence-based design of distance education modules requires an in-depth discussion with the curriculum designers. At this stage, it appears that teaching "online" or "distance" mode of certain generic or subject-specific competences poses a challenge; even more so, the assessment of these competences poses a special challenge. There seems to be a general consensus that a competence and outcome-oriented, student-centred teaching and learning in higher education should consider distance education only as a complementary mode to fill the gaps of face-to-face teaching. The quality guidelines for distance education developed by the African Council for Distance Education (ACDE) may help enrich further endeavours in the Tuning Higher Education in Africa and also consider this mode of teaching in higher education reform efforts. ${ }^{32}$

Harmonization is necessary to strengthen the competitiveness and integration of the continent. However, if harmonization is not flanked by

${ }^{32}$ African Council for Distance Education (ACDE), http://www.acde-africa.org/. 
enhancement of quality of teaching and learning in the African higher education "mass" system, it may have some negative implications on the attractiveness of the academic workplace, the employability of graduates, and an asymmetric flow of "brains" within Africa-leading to the reverse effect of regional integration. Regional integration and reform of higher education efforts should be balanced in developing globally competitive "lighthouses" and regional relevant institutions. Hence, harmonization endeavours must have an external perspective as well as an "internal", continental perspective with quality as common denominator.

Initially, the Tuning Africa initiative was promoted by political convictions of regional integration, mobility, and harmonization. At the launch of the initiative, concerns were raised about ownership, inclusiveness, leadership and strategy. In a direct response to, and accord of the reaction, it was agreed to start the initiative with a feasibility study. The feasibility and later the pilot studies have been instrumental in effectively addressing those issues and concerns.

As the Tuning process needs to involve numerous and diverse stakeholders - such as administrators, ministries, higher education and quality assurance agencies, policy makers, employers and the public sector, students, regional bodies, intermediary actors and university associations - it has become increasingly clear for a close and continuous consultation over a sustained period of time.

A plethora of national and regional quality assurance, accreditation, qualification frameworks, credit accumulation and credit transfer systems, and curricula reforms abound. What remains to be done is to ensure that these efforts are effectively integrated and synchronized to create coherence and consistency.

Implementing harmonization and tuning requires resources. As most African universities experience chronic financial constraints, the provision of resources still has to be negotiated by numerous constituencies. The success of the initiative may also be hampered by the disparate institutional infrastructure and weak human resources base in many institutions.

Tuning still remains a new lexicon in the African higher education landscape. In the "Tuning Africa" pilot project, some five dozen universities were involved - and this comprises a small critical mass of champion universities, along with supporting political and intermediary bodies. Therefore a sound, appropriate and persistent dissemination strategy to popularize the initiative is imperative. For instance, the Tuning Medicine Group has already developed a strategy to disseminate the experiences and results of the pilot project to respective national higher education councils, associations, academic conferences, as well as regional economic communities (RECs) and university associations. 
The successful implementation of a paradigm shift from input-oriented teaching to outcome-oriented learning - with all its associated implications to competence assessment and quality assurance-remains a key challenge to "Tuning Africa". The rapid "massification" of higher education, meagre and overstretched resources, poor management and leadership, underqualified staff and under-prepared students will pose imminent threat to its success. Therefore appropriate, contextualized, and realistic approaches need to be put in place as Tuning Africa is moving forward, into the next expanded phase where the experiences and outcomes so far acquired need to be effectively and widely disseminated. As the dialogue on credits and a common credit system is one of the central pillars of the Tuning approach, the pilot project may play a positive role in advancing the African Credit (Transfer) System.

The methodology of developing profiles and programs of generic and subject specific competences is time intensive. Thus, the pilot phase of 14 months turned out to be a little short to develop the programs in full, for instance, per each study year. The dialogue on competences to be achieved in the different study years, the discussion on teaching methodologies, assessment, work-load based credits and the overall link to the institutional quality management system need further time. The need for a lengthy dialogue in strongly regulated professions with a diverse stakeholder landscape - such as medicine, engineering, and teacher education-are palpable. The systematic involvement of the stakeholders from the public sector (e.g. ministries, regulatory bodies) and the academic sector (e.g. "lead" universities, agencies, networks, academic associations, student bodies, teacher unions) to the private sector (e.g. professional associations and employer associations, industry, organized lobbyists) demand a wellcoordinated dialogue that should be strongly supported by the university leadership and encouraged by ministries.

To be sure, designing programs in a learner-centred outcome-oriented way that facilitates employability of graduates - in a fast moving knowledge train - is a complex and demanding process. Guaranteeing relevance can only be achieved if all stakeholders are regularly engaged and consulted in evaluations and reform endeavours. In some disciplines or thematic areas the diversity of the stakeholders make reform efforts even more dauntingnecessitating the need for creating a spirit of common values and engagement across numerous stakeholder boundaries.

Policy on continental level is clear, but there is more commitment needed to implement similar initiatives on regional, national and institutional levels. A clear strategy of dissemination for 2014 has been laid out by the main players of the project (AUC, EU, AAU, intermediary bodies and the Tuning Higher 
Education in Africa Steering Committee), to help promote sustainability and diffusion of the Tuning methodology. Strong recommendations have been voiced to link and embed other reform efforts, for instance, in quality assurance, accreditation, curriculum development, and the development of (regional) qualification frameworks with the Tuning methodology.

The Tuning Higher Education in Africa pilot project has created an inclusive, effective and systematic consultative process that fostered discourse at grassroots level across borders through a number of meetings, regional seminars and conferences. These will undoubtedly contribute in advancing quality assurance, improvement of teaching and learning, and assessment - and harmonization of higher education in Africa.

\section{Bibliography}

African Council for Distance Education (ACDE). http://www.acde-africa.org/.

African Union Commission. "Harmonization of Higher Education Programmes in Africa: A Strategy for the African Union." COMEDAF III's Work Document $\mathrm{N}^{\circ}$ AU/EXP/EDUC/2 (III), Part II. Addis Ababa: African Union (AU), 2007. http:// www.africa-eu-partnership.org/higher-education.

Arab Network for Quality Assurance in Higher Education (ANQAHE). http://www. anqahe.org/.

Association of Arab Universities (AARU). http://www.aaru.edu.jo/.

Badrawi, Nadia. "Quality Assurance in Higher Education: Perspective from the Arab Region." Paper presented at the Africa Union Commission, Addis Ababa (Ethiopia), 10-12 April 2013.

Beneitone, Pablo. "Generic Competences: Consultation with Stakeholders in Africa. Some Results and a Comparison with Other Regions." Paper presented at the Joint Africa-EU Strategy Tuning Seminar, Cape Town, 15 May 2012. http:// www.tuningafrica.org/images/stories/documentos/africa_presentacion_cape_ town_pablo_2012_generic_competences.pdf.

Beneitone, Pablo, Cesar Esquetini, Julia González, Maida Marty Maleta, Gabriela Siufi, and Robert Wagenaar, eds. Reflections on and Outlook for Higher Education in Latin America. Final Report - Tuning Latin America Project 2004-2007. Bilbao: University of Deusto and University of Groningen, 2007.

Diarra, Mohamed Chérif. "Arusha Convention on the Recognition of Studies, Certificates, Diplomas, Degrees and Other Qualifications in Higher Education in African States. Synthesis Report.” UNESCO Dakar Regional Office (BREDA), 2011. http://www.adea-wgemps.org/index.php/documents/reports/doc_ view/163-arusha-convention-synthesis-report-24-may-2011.html.

East African Community (EAC). "Protocol on the Establishment of the East African Community Common Market." Intergovernmental Agreement. Arusha (Tanzania): EAC, 2009. http://www.commonmarket.eac.int/documentation/ doc_view/48-common-market-protocol.raw?tmpl=component. 
Economic Community of West African States (ECOWAS). "Regional Convention on the Recognition and Equivalence of Qualifications." 2002. http://www. comm.ecowas.int/dept/stand.php?id=e_e1_brief.

—. "Review of ECOWAS Protocols and Policy Documents." 2010. http://xa. yimg.com/kq/groups/17509343/147236731/name/Matrix.

_. "Strategic Plan 2011-2015." Abuja: ECOWAS Commission, 2010. http:// www.spu.ecowas.int/wp-content/uploads/2010/06/REGIONAL-STRATEGICPLAN-RFV-in-English.pdf.

European Union Commission, and African Union Commission. "Joint Africa-EU Action Plan 2011-2013.” 2011. http://www .africa-eu-partnership.org/sites/ default/files/doc_jaes_action_plan_2011_13_en.pdf.

González, Julia, and Robert Wagenaar, eds. Tuning Educational Structures in Europe. Universities' Contribution to the Bologna Process. An Introduction. 2nd ed. Bilbao: Universidad de Deusto, 2008.

Hahn, Karola. "Towards a SADC Area of Higher Education.” NEPRU Research Report No. 30. Windhoek: Namibian Economic Policy Research Unit (NEPRU), 2005. http://wwwisis .unam.na/hivdocs/UNICEF/Socio-economic/NEPRU/ NRR30_Towards\%20SADC\%20era\%20of\%20higher\%20education.pdf.

Hahn, Karola, and Damtew Teferra. "Harmonization and Tuning: Integrating African Higher Education." International Higher Education, no. 69, Fall (September 2012): 20-22.

- "Harmonization and Tuning: Integrating the Space of African Higher Education." International Network for Higher Education in Africa (INHEA) Editorial Series (January 2012). Boston: Center for International Higher Education (CIHE), Boston College, 2012. https://htmldbprod.bc.edu/prd/ f?p=2290:4:0::NO:RP,4:P0_CONTENT_ID:116932.

Hoosen, Sarah, Neil Butcher, and Beatrice Khamati Njenga. "Harmonization of Higher Education Programmes: A Strategy for the African Union." African Integration Review 3, no. 1 (January 2009): 1-26.

Inter-University Council for East Africa (IUCEA). http://www.iucea.org/.

Mtasiwa, Benedict. "Progress on Development or Harmonization of Quality Assurance Systems, Credit Accumulation and Transfer System (CATS) and the East African Qualifications Framework (EAQF)." Inter-University Council for East Africa (IUCEA), 2011. http://www.africa-eu-partnership.org/sites/default/ files/tuning_senega_en.pdf.

Oyewole, Olusola. "African Harmonisation: An Academic Process for a Political End?" In Chronicle of African Higher Education [e-bulletin], January 2013, edited by Damtew Teferra. Boston: Center for International Higher Education (CIHE), Boston College, 2013. https://htmldbprod.bc.edu/prd/f?p= 2290:4:0::NO:RP,4:P0_CONTENT_ID:119500.

- "Harmonisation of Degree Structures, and Regional Qualifications Frameworks in the African Higher Education Space." Paper presented at the COREVIP AAU Conference, Stellenbosch (South Africa), May 30 - June 3, 2011. http://events.aau.org/userfiles/file/corevip11/papers/olusola_oyewole_ Creating_AHES.pdf. 
Shabani, Juma. "Quality Regimes in Africa: The Reality and the Aspirations." In Chronicle of African Higher Education [e-bulletin], May 2013, edited by Damtew Teferra. Boston: Center for International Higher Education (CIHE), Boston College, 2013. https://htmldbprod.bc.edu/prd/f?p=2290:4: 0::NO:RP,4:P0_CONTENT_ID:119954.

Southern African Development Community (SADC). "Protocol on Education and Training in the Southern African Development Community (SADC)." 1997. http://www.sadc.int/files/3813/5292/8362/Protocol_on_Education_Training1997.pdf.

Teferra, Damtew. "Harmonization and Tuning: The African Experience." Paper presented at the Africa-EU Joint Policy Workshop 'On Linking Institutional Evaluation Practices. Quality Rating Mechanisms and Reinforcing Quality Assurance at Continental Level', Accra (Ghana), 18-19 December 2012.

. "Pan African University: Rescuing the Vision." International Network for Higher Education in Africa (INHEA) Editorial Series (June 2012). Boston: Center for International Higher Education, Boston College, 2012. https:// htmldbprod.bc.edu/prd/f?p=2290:4:0::NO:RP,4:P0_CONTENT_ID:118382.

Tuning Africa. "Feasibility Study into the Relevance of a Tuning Approach for Higher Education in Africa. Final Report. April 2011." Tuning Africa, 2011. http://www.tuningafrica.org/index.php?option=com_content\&view=article\&id $=2 \&$ Itemid $=105 \&$ lang=en.

— . "Final Report of Agriculture." Paper presented at the Joint Africa-EU Strategy Tuning Seminars. Fourth General Meeting, Nairobi, 23-25 January 2013. http://www.tuningafrica.org/images/stories/documentos/booklet_nairobi_ ingles_subir.pdf.

_ . "Final Report of Civil Engineering." Paper presented at the Joint Africa-EU Strategy Tuning Seminars. Fourth General Meeting, Nairobi, 23-25 January 2013. http://www.tuningafrica.org/images/stories/documentos/booklet_nairobi_ ingles_subir.pdf.

_ "Final Report of Mechanical Engineering." Paper presented at the Joint Africa-EU Strategy Tuning Seminars. Fourth General Meeting, Nairobi, 23-25 January 2013. http://www.tuningafrica.org/images/stories/documentos/booklet_ nairobi_ingles_subir.pdf.

_. "Final Report of Medicine." Paper presented at the Joint Africa-EU Strategy Tuning Seminars. Fourth General Meeting, Nairobi, 23-25 January 2013. http:// www.tuningafrica.org/images/stories/documentos/booklet_nairobi_ingles_ subir.pdf.

— .Final Report of Teacher Education." Paper presented at the Joint Africa-EU Strategy Tuning Seminars. Fourth General Meeting, Nairobi, 23-25 January 2013. http://www.tuningafrica.org/images/stories/documentos/booklet_nairobi_ ingles_subir.pdf.

- .Presentation of Final Report of 5 Subject Areas. Final Report 2011-2013." Paper presented at the Joint Africa-EU Strategy Tuning Seminars, Nairobi, 23 January 2013. http://www.tuningafrica.org/images/stories/documentos/sag_ presentation_nairobi_january\%202013.pdf. 
Tuning Educational Structures in Europe (Tuning Europe). http://www.unideusto. org/tuningeu/.

United Nations Organization for Education, Science and Culture (UNESCO). "2009 World Conference on Higher Education.” UNESCO, 2009. http://www.unesco. org/en/wche2009/.

—. "Regional Convention on the Recognition of Studies, Certificates, Diplomas, Degrees and Other Academic Qualifications in Higher Education in the African States.” UN Treaty Series No. 21522. Adopted at Arusha, 5 December 1981: UNESCO, 1981. http://www.unesco.org/education/studyingabroad/tools/ conventions_afr_cover.shtml.

Villa Sanchez, Aureli, and Manuel Poblete Ruiz, eds. Competence-Based Learning. A Proposal for the Assessment of Generic Competences. Bilbao: University of Deusto, 2008.

Woldetensae, Yohannes. "The Overall Landscape of Quality Assurance and Accreditation in Africa." Paper presented at the workshop "Establishment of a Continental Accreditation Agency for Higher Education in Africa", African Union Commission, Addis Ababa, 10 - 11 April 2013.

World Bank (WB). Accelerating Catch-Up. Tertiary Education for Growth in SubSaharan Africa. Washington, D.C.: The World Bank Group, 2009.

. Constructing Knowledge Societies: New Challenges for Tertiary Education. Washington, D.C.: The World Bank Group, 2002.

—. "Fact Sheet. The World Bank and Agriculture in Africa." http://web. worldbank.org/WBSITE/EXTERNAL/COUNTRIES/AFRICAEXT/0,,content MDK:21935583 pagePK:146736 piPK:146830 theSitePK:258644,00.html. 


\section{Annex}

The Subject Area Group "Teacher Education" identified the following 31 subject-specific competences clustered in the meta-profile given in Chapter 9:

\section{A) Competences related to Knowledge}

Understanding of

1. The subject(s) to be taught

2. The underlying principles of the foundations of education

3. Pedagogical knowledge of specific subject areas

4. The local and international social, political, economic, cultural and environmental contexts of education

5. National and institutional policies relating to education

6. The language(s) of instruction

B) Competences related to Educational Practice and Skills

Ability to

7. Develop schemes of work and teaching plans

8. Select, adapt and use appropriate teaching methods and learning activities

9. Use a range of assessment skills to set, mark and grade learners' achievement

10. Develop and use teaching, learning and assessment materials, including appropriate ICTs

11. Identify and attend to learners' needs

12. Manage learners both inside and outside formal classroom contexts

13. Develop own and learners' entrepreneurial skills

14. Create conducive learning environments that encourage learning

15. Use language appropriately in the classroom and in the subject

16. Conceptualize, analyse situations to solve problems

17. Participate in basic educational research

18. Manage time effectively

19. Critically reflect on their work to improve practice

20. Adapt to change

C) Competences related to Values and Ethics

Ability to

21. Care for and support the well-being of all learners 
22. Respect socio-cultural diversities (religious, ethnic, linguistic, gender, economic, etc.)

23. Adhere to the rules and regulations of the profession and institution

24. Maintain equity and fairness among learners and promote inclusive education

25. Continuously upgrade their own knowledge and skills

26. Be a role model

27. Inspire self-confidence and appreciation of cultural heritage in learners

D) Interpersonal competences

Ability to

28. Be sensitive to the feelings of others

29. Collaborate and network with others, including peers, head teachers, professional groups, and parents

30. Communicate effectively with different audiences and using appropriate tools, including ICTs and relevant forms of discourse

31. Lead and manage groups 